\title{
Trends in rates of occupational fatal injuries in the United States (1983-92)
}

\author{
A John Bailer, Leslie T Stayner, Nancy A Stout, Laurence D Reed, Stephen J Gilbert
}

\begin{abstract}
Objectives-An updated version of a national surveillance system of traumatic occupational fatalities was used to explore adjusted and unadjusted trends in rates of fatal injury.

Methods-Data from the national traumatic occupational fatalities surveillance system were combined with data on employment from the United States Bureau of Labor Statistics. Poisson regression was then used to examine trends in rates of occupational fatality injuries while controlling for demographic and workplace characteristics.

Results-Adjusted annual changes in rates of fatal injuries ranged from a decline of $6.2 \%$ for workers in technical and administrative support occupationsfor example, health, science, and engineering technicians, pilots, computer programmers-to an increase of $1.6 \%$ in machine operators, assemblers, and inspectors. For industries, annual changes ranged from a decline of $5.3 \%$ for workers in public administration-for example, justice, public order, and safety workers-to an increase of $2.6 \%$ for workers in the wholesale trade. By comparison, the annual decline over all industries and occupations was $3.1 \%$. In many industries and occupations, an effect modification of annual trends by the age of the worker was also found with the oldest workers experiencing either no decline or a significant increase in rates of fatal injuries.

Conclusions-This general pattern of decline, adjusted for the effects of demographic characteristics of the worker population, is encouraging; however, increases in rates of fatal injuries found in particular industries and occupations, suggest appropriate targets for increased injury prevention efforts.

(Occup Environ Med 1998;55:485-489)
\end{abstract}

Keywords: epidemiology; Poisson regression

About 6300 workers died in the United States every year during the 1980 s in occupational fatal injuries, which translates to about seven fatalities per 100000 workers. $^{12}$ The mere magnitude of this statistic reflects the public health significance of occupational fatal injury and the importance of efforts to mitigate the factors that contribute to fatal injuries.

The National Institute for Occupational Safety and Health (NIOSH) National Traumatic Occupational Fatalities (NTOF) surveil- lance system has accumulated over a decade of experience (since 1980) tracking rates of occupational fatal injuries. Previous research has investigated trends in rates of occupational fatal injuries over calendar years $1980-5^{3}$ and over years $1980-9^{2}$ by demographic characteristics such as race, sex, and age and by different industry and occupational groups. An updated version of the NTOF data is used in conjunction with employment estimates to explore whether trends in rates of fatal injuries exist above and beyond differences that might be explained by changes in demographic, industry, or occupational characteristics. Also, model based estimates of trends in fatal injuries are obtained.

\section{Methods}

Data from the NTOF database were combined with data on employment from the United States Bureau of Labor Statistics (BLS) to compute injury rates for these analyses. The NTOF database is a death certificate based census of occupational fatal injuries in the United States containing case data of deaths including year of death, sex, race (white, black, other), age (collapsed into 11 intervals for our analysis), industry, and occupation. Levels of the industry classification correspond to the main standard industrial classification sectors ${ }^{4}$ whereas the levels of the occupation classification are from the census occupational classification system. ${ }^{5}$ (Table 3 shows a description of the industry and occupation groupings used in this analysis.) The BLS employment data were based on unpublished data tabulated from the current population survey ${ }^{6}$ constructed in response to an agreement between BLS and NIOSH. Potential biases and shortcomings associated with these data sources are discussed in the final section of this manuscript. Note that if biases are constant-for example, the numerators are a systematic undercount but the degree of undercounting is the same from year to yearthen this should not adversely affect an assessment of trends.

We modelled rates of occupational fatal injuries as an explicit function of year to formally evaluate trend with adjustments for other predictors. Poisson regression models, a generalised linear model with a log link, and a Poisson response distribution were used. ${ }^{7-10}$ These $\log$ linear models represent log rates as linear functions of predictor variables of interest. The rate in this analysis is simply the number of fatal occupational injuries divided by the number at risk (person-years).

In this analysis, we consider regression models of the trends in rates of occupational fatal 
Table 1 Unadjusted rates for year and for the predictor variables (sex, race, industry, occupation, and age) pooled over the other factors

\begin{tabular}{|c|c|c|c|}
\hline Factor & $\begin{array}{l}\text { Rate } \\
\text { (/100000) }\end{array}$ & $\operatorname{Dead}(n(\%))$ & $\begin{array}{l}\text { Person-years } \\
(n(\%))\end{array}$ \\
\hline \multicolumn{4}{|l|}{ Year: } \\
\hline 1983 & 5.23 & $5290(10.2)$ & $101072344(9.0)$ \\
\hline 1984 & 5.29 & $5563(10.7)$ & $105225374(9.4)$ \\
\hline 1985 & 5.30 & $5690(10.9)$ & $107268080(9.6)$ \\
\hline 1986 & 4.68 & $5135(9.9)$ & $109695639(9.8)$ \\
\hline 1987 & 4.77 & $5363(10.3)$ & $112489224(10.0)$ \\
\hline 1988 & 4.62 & $5310(10.2)$ & $115001304(10.3)$ \\
\hline 1989 & 4.43 & $5205(10.0)$ & $117418181(10.5)$ \\
\hline 1990 & 4.26 & $5023(9.7)$ & $117904867(10.5)$ \\
\hline 1991 & 4.14 & $4836(9.3)$ & $116886312(10.4)$ \\
\hline 1992 & 3.87 & $4549(8.8)$ & $117546463(10.5)$ \\
\hline \multicolumn{4}{|l|}{ Sex: } \\
\hline Female & 0.61 & $3045(5.9)$ & $501999768(44.8)$ \\
\hline Male & 7.91 & $48919(94.1)$ & $618508020(55.2)$ \\
\hline \multicolumn{4}{|l|}{ Race: } \\
\hline Black & 4.82 & $5385(10.4)$ & $111718007(10.0)$ \\
\hline Other & 3.85 & $1310(2.5)$ & $34060961(3.0)$ \\
\hline White & 4.64 & $45269(87.1)$ & $974728820(87.0)$ \\
\hline \multicolumn{4}{|l|}{ Industry: } \\
\hline Agriculture, forestry, and fishing & 19.46 & $6607(12.7)$ & $33949547(3.0)$ \\
\hline Mining & 26.52 & $2156(4.1)$ & $8128390(0.7)$ \\
\hline Construction & 14.40 & $10360(19.9)$ & $71938098(6.4)$ \\
\hline Manufacturing & 3.78 & $7882(15.2)$ & $208276402(18.6)$ \\
\hline Transport and public utilities & 12.62 & $9862(19.0)$ & $78157226(7.0)$ \\
\hline Wholesale trade & 2.89 & $1308(2.5)$ & $45215709(4.0)$ \\
\hline Retail trade & 2.49 & $4650(8.9)$ & $187061585(16.7)$ \\
\hline Finance, insurance, and real estate & 1.04 & $779(1.5)$ & $74851231(6.7)$ \\
\hline Services & 1.60 & $5758(11.1)$ & $360246400(32.2)$ \\
\hline Public administration & 4.94 & $2602(5.0)$ & $52683200(4.7)$ \\
\hline \multicolumn{4}{|l|}{ Occupation: } \\
\hline \multicolumn{4}{|l|}{ Executive, administration, and } \\
\hline $\begin{array}{l}\text { management } \\
\text { Professional }\end{array}$ & $\begin{array}{l}2.83 \\
1.43\end{array}$ & $\begin{array}{l}3849(7.4) \\
2107(4.1)\end{array}$ & $\begin{array}{l}134926343(12.0) \\
147060718(13.1)\end{array}$ \\
\hline Technical and related support & 0.30 & $1515(2.9)$ & $35252263(3.1)$ \\
\hline Sales occupations & 2.56 & $3414(6.6)$ & $133621659(11.9)$ \\
\hline Administrative support including clerical & 0.56 & $997(1.9)$ & $178244294(15.9)$ \\
\hline Service occupations & 2.53 & $3823(7.4)$ & $151204105(13.5)$ \\
\hline Farming, forestry, and fishing & 20.26 & $7085(13.6)$ & $34970241(3.1)$ \\
\hline Precision production, craft, and repair & 8.02 & $10686(20.6)$ & $133167970(11.9)$ \\
\hline Machine operators, assembly, and & & & \\
\hline inspectors & 2.73 & $2158(4.2)$ & $79064780(7.1)$ \\
\hline Transport, material moving & 21.84 & $10229(19.7)$ & $46830853(4.2)$ \\
\hline Handlers, helpers, labourers & 13.22 & $6101(11.7)$ & $46164562(4.1)$ \\
\hline \multicolumn{4}{|l|}{ Age categories: } \\
\hline $16-19$ & 1.98 & $1255(2.4)$ & $63476983(5.7)$ \\
\hline $20-24$ & 3.93 & $5207(10.0)$ & $132500110(11.8)$ \\
\hline $25-29$ & 4.34 & $6961(13.4)$ & $160344692(14.3)$ \\
\hline $30-34$ & 4.32 & $7010(13.5)$ & $162134537(14.5)$ \\
\hline $35-39$ & 4.14 & $6130(11.8)$ & $148151494(13.2)$ \\
\hline $40-44$ & 4.35 & $5494(10.6)$ & $126435946(11.3)$ \\
\hline $45-49$ & 4.62 & $4626(8.9)$ & $100133645(8.9)$ \\
\hline $50-54$ & 5.12 & $4189(8.1)$ & $81754944(7.3)$ \\
\hline $55-59$ & 6.13 & $4210(8.1)$ & $68641761(6.1)$ \\
\hline $60-64$ & 6.66 & $3024(5.8)$ & $45413500(4.1)$ \\
\hline$\geqslant 65$ & 12.24 & $3858(7.4)$ & $31520176(2.8)$ \\
\hline
\end{tabular}

injuries both as a function of year unadjusted for any other predictor variable and as a function of year and worker characteristics (race, age, sex). The model in which trend in rates of fatal injuries is evaluated unadjusted for other predictor variables can be written as:

$\log$ (injury rate) $=\beta_{0}+\beta_{1}$ (year-83)

(As a technical aside, we used a model in which year was scaled by subtracting the first year in the data set from each year to provide a natural interpretation of the intercept $\beta_{0}-\exp \left(\beta_{0}\right)$ to represent the fatality rate in 1983.)

The adjusted assessment of trend in rates of fatal injuries involved fitting a series of models that included year and each of the other variables, first for all industries and occupations combined, and then for each level of industry and for each level of occupation. This adjusted model can be written as:

$\log$ (injury rate) $=\beta_{0}+\beta_{1}($ year -83$)+$ $f($ race, sex, age) where race is a three level categorical variable; sex is a two level categorical variable, age is an 11 level categorical variable, and $f$ (race, sex, age) is a linear combination of indicator variables (see Bailer et $a l^{10}$ ). In this model, injury rates are constructed separately for each year race-sex-age combination within each industry or occupation. We did not adjust the analysis for industry trends for occupation. As a shift of occupations within an industry represents a change in the industry, we thought that the assessment of fatal injury trends in each industry pooled over all occupations within that industry was the appropriate analysis. Similarly, we did not think that the adjusted analysis of fatal injury trends within occupation should be adjusted for industry. Note that the model described in equation (2) implies that the trend in injury rates within each industry or occupation is the same for each age-sex-race combination. We examined this assumption by testing for interactions between year and each of age, race and sex (see Bailer et al ${ }^{10}$ for details on the assessment of effect modification in these models). Neither sex nor race seemed to be an effect modifier of year; however, the ageyear interactions in these models were significant in seven of 10 industries and four of 11 occupations. More discussion of this effect is presented later.

Finally, we also examined the trend for all levels of each factor adjusted for all other factors. For example, we fitted the following model:

$\log ($ injury rate $)=\beta_{0}+\beta_{1}($ year -83$)+f($ race, age, industry, occupation)

for each level of the sex variable (separate model fits for men and women). The coefficient $\beta_{1}$ corresponds to the trend in log injury rates for men or women adjusted for race, age, industry, and occupation changes. Analogous models were also fitted for race, age, industry, and occupation levels.

The percentage annual decrement, both for the adjusted and unadjusted analyses, is constructed as $100 \times\left(1-\mathrm{e}^{\text {trend parameter estimate }}\right)$ where the trend parameter estimate is the fitted value of $\beta_{1}$. The SAS procedure GENMOD $^{9}$ was used to fit all of these models.

\section{Results}

Table 1 shows a summary compilation of fatal injury counts and number employed over the years 1983-92 displayed by levels of each of the predictor variables. Over this time 51964 occupational fatal injuries were found in the United States among the 1120507788 person-years of employment.

The unadjusted rate of occupational fatal injuries has declined over the years 1983-92. After remaining at about 5.3 deaths per 100000 workers over the first three years of this interval, the rate was $<5$ deaths per 100000 workers thereafter with the minimum rate over this period occurring in 1992 (3.87 deaths per 100 000). The fatal injury rate for men was about 13 times the fatal injury rate for women $(7.91 v 0.61$ per 100000$)$. The rates of fatal injuries for black and white workers were similar, $4.82 v 4.64$ per 100 000, respectively, 
Table 2 Trend estimates for each factor adjusted for all other factors (the p value associated with a test of no trend along with an estimate of the annual decline in rates of fatal injury for each factor level are given in the body of the table)

\begin{tabular}{|c|c|c|}
\hline Factor & $p$ Value & $\begin{array}{l}\text { Estimated annual } \\
\text { decline (\%) }\end{array}$ \\
\hline \multicolumn{3}{|l|}{ Sex: } \\
\hline Female & 0.0158 & 1.53 \\
\hline Male & 0.0001 & 2.81 \\
\hline \multicolumn{3}{|l|}{ Race: } \\
\hline Black & 0.0002 & 1.79 \\
\hline Other & 0.1415 & 1.41 \\
\hline White & 0.0001 & 2.85 \\
\hline \multicolumn{3}{|l|}{ Industry: } \\
\hline Agriculture, forestry, and fishing & 0.0001 & 2.48 \\
\hline Mining & 0.0001 & 3.34 \\
\hline Construction & 0.0001 & 3.21 \\
\hline Manufacturing & 0.1704 & 0.54 \\
\hline Transport and public utilities & 0.0001 & 5.40 \\
\hline Wholesale trade & 0.0314 & -2.11 \\
\hline Retail trade & 0.7163 & 0.19 \\
\hline Finance, insurance, and real estate & 0.0057 & 3.44 \\
\hline Services & 0.0001 & 2.37 \\
\hline Public administration & 0.0001 & 5.48 \\
\hline \multicolumn{3}{|l|}{ Occupation: } \\
\hline Executive, administration, and management & 0.0001 & 5.11 \\
\hline Professional & 0.0012 & 2.44 \\
\hline Technical and related support & 0.0001 & 6.64 \\
\hline Sales occupations & 0.9591 & -0.03 \\
\hline Administrative support including clerical & 0.3614 & 1.00 \\
\hline Service occupations & 0.0001 & 2.32 \\
\hline Farming, forestry, and fishing & 0.0225 & 0.94 \\
\hline Precision production, craft, and repair & 0.0006 & 1.17 \\
\hline Machine operators, assembly, and inspectors & 0.0546 & -1.47 \\
\hline Transport, material moving & 0.0001 & 4.85 \\
\hline Handlers, helpers, labourers & 0.0001 & 5.81 \\
\hline \multicolumn{3}{|l|}{ Age: } \\
\hline $16-19$ & 0.0001 & 5.92 \\
\hline $20-24$ & 0.0001 & 4.23 \\
\hline $25-29$ & 0.0001 & 3.15 \\
\hline $30-34$ & 0.0001 & 3.36 \\
\hline $35-39$ & 0.0001 & 3.56 \\
\hline $40-44$ & 0.0001 & 2.75 \\
\hline $45-49$ & 0.0001 & 1.97 \\
\hline $50-54$ & 0.0134 & 1.32 \\
\hline $55-59$ & 0.0001 & 2.38 \\
\hline $60-64$ & 0.2594 & 0.72 \\
\hline$\geqslant 65$ & 0.4312 & 0.44 \\
\hline
\end{tabular}

with the rates for other racial groups lower at 3.85 per 100000 . The industries mining, agriculture, forestry, fishing, and construction had the highest unadjusted rates of fatal injuries whereas finance, insurance, and real estate had the lowest. The occupations with the highest rates of fatal injuries were transportation and material moving and farming, forestry, and fishing whereas administrative support including clerical was the occupation with the lowest unadjusted rate of fatal injuries. Injury rates increased by a factor of two from the lowest age category, 16 to 19 year olds, through the next five age intervals (20 to 44 years of age). After age 44 , the rates began to rise with the highest rate of fatal injuries occurring in the oldest workers (age $\geqslant 65$ ).

Table 2 shows the estimated annual percentage declines from the Poisson regression models for all levels of each factor adjusted for all other factors. We see that both men and women experienced significant declines in rates of fatal injuries with the decline for men almost twice that of women. Both black and white workers had significant declines in rates of fatal injuries; however, other races did not decline significantly. All industries except manufacturing and real estate experienced significant trends with all declining except for wholesale trades which experienced a $2.1 \%$ annual increase in the rate of fatal injuries adjusted for all other factors. All occupations except sales and administrative support including clerical had significant declines with all but machine operators, assemblers, and inspectors experiencing a decline. A decline in rates of fatal injuries was found in all age categories except in workers $\geqslant 60$. Also, the size of the annual decline decreased with age.

With all industries and occupations pooled, an annual decline of $3.4 \%$ a year $(95 \%$ confidence interval ( $95 \% \mathrm{CI}) 3.11 \%$ to $3.69 \%$ ) was found in rates of fatal injuries based on fitting an unadjusted model to rates of fatal injuries. Applying the race-sex-age adjusted model to all industries and occupations combined resulted in an estimated annual decrement of $3.1 \%$ a year (95\% CI $2.79 \%$ to $3.38 \%$ ). The goodness of fit of the regression model was also significantly improved by the consideration of race, sex, and age.

Table 3 and the figure show the trend estimates and estimated annual percentage declines from the Poisson regression models (both unadjusted and adjusted for sex, race, and age) for each industry or occupation category. It is worth noting that the tests of the significance for the age, race and sex effects yielded $p$ values $<0.05$ (with 29 of 30 tests having a $\mathrm{p}$ value $<0.005$ ) for the industry analysis, and $p$ values $<0.05$ (with 29 of 33 tests having a $p$ value $<0.005$ ) for the occupational analysis. The significance of the age, sex, and race terms provides evidence of their potential importance for the analysis of trends.

A general decline in rates of fatal injuries was found across most industries (nine of 10 industries) and occupations (nine of 11 occupations) in both the adjusted and unadjusted analyses. Changes over the 10 industry groups ranged from a significant decline of $5.3 \%$ a year in public administration to a significant increase of $2.6 \%$ in the wholesale trade. Annual changes over the 11 occupational categories ranged from a significant decline of $6.2 \%$ a year in technicians and related support to a significant increase of $1.6 \%$ a year in machine operators, assemblers, and inspectors. In the retail trade industry, the direction of the trend changed from decreasing rates (adjusted) to increasing rates (unadjusted); however, the trend was not significant in either the adjusted or unadjusted analyses. One caveat should be raised in discussing these trends. As noted previously, age seemed to be an effect modifier of the time trend in seven of 10 industries (except for agriculture, forestry and fishing; mining; and retail trade), and in four of 11 occupations (including technical and related support; precision products, crafts and repair; transportation and material moving; and handlers, helpers, and labourers). We explored the nature of this effect modification by fitting a model similar to model (2) with the addition of a term corresponding to the interaction of year and age. In general, when this interaction was significant, the trend for workers age $\geqslant 65$ was positive (increasing rates) or not changing whereas the trend for younger workers was negative. Thus the results presented in table 3 represent the trend pooled over workers of all ages, and we might expect greater declines than 
Table 3 Parameter estimates associated with year, $p$ values, and estimated annual declines in rates of fatal injury associated with different industry or different occupation based on sex, race, and age adjusted and unadjusted models

\begin{tabular}{|c|c|c|c|c|c|c|c|}
\hline & \multirow[b]{2}{*}{ Description (eg) } & \multicolumn{3}{|c|}{ Adjusted $t$} & \multicolumn{3}{|c|}{ Unadjusted $\dagger$} \\
\hline & & $E s t^{\star}$ & $p$ Value & $\begin{array}{l}\% \\
\text { Decline }\end{array}$ & Est & p Value & $\begin{array}{l}\% \\
\text { Decline }\end{array}$ \\
\hline \multicolumn{8}{|l|}{ Industry: } \\
\hline Public administration & $\begin{array}{l}\text { Justice, public order and safety, human } \\
\text { resources administration, environmental } \\
\text { quality and housing, economic programmes }\end{array}$ & -0.055 & $<0.001$ & 5.3 & -0.063 & $<0.001$ & 6.1 \\
\hline Transport and public utilities & $\begin{array}{l}\text { Railway, taxis, lorries, water, and air } \\
\text { transport }\end{array}$ & -0.049 & $<0.001$ & 4.8 & -0.054 & $<0.001$ & 5.3 \\
\hline Finance, insurance, and real estate & $\begin{array}{l}\text { Banks, brokers, insurance agents, real estate } \\
\text { agents }\end{array}$ & -0.035 & 0.006 & 3.4 & -0.035 & 0.006 & 3.4 \\
\hline Construction & $\begin{array}{l}\text { General contractor, heavy construction, } \\
\text { special trade construction }\end{array}$ & -0.033 & $<0.001$ & 3.2 & -0.033 & $<0.001$ & 3.3 \\
\hline Mining & Metal, coal, oil and gas, sand and gravel & -0.026 & 0.001 & 2.6 & -0.035 & $<0.001$ & 3.5 \\
\hline Services & Hotels, car repair, miscellaneous repair & -0.023 & $<0.001$ & 2.3 & -0.025 & $<0.001$ & 2.5 \\
\hline Agriculture, forestry, and fishing & Crops, livestock & -0.023 & $<0.001$ & 2.2 & -0.023 & $<0.001$ & 2.2 \\
\hline Manufacturing & $\begin{array}{l}\text { Food products, textile, timber, furniture, } \\
\text { stone, metal }\end{array}$ & -0.006 & 0.125 & 0.6 & -0.008 & 0.051 & 0.8 \\
\hline Retail trade & $\begin{array}{l}\text { Building materials, general merchandise, } \\
\text { food stores, car dealers, apparel stores, } \\
\text { furniture, eating and drinking places }\end{array}$ & -0.002 & 0.695 & 0.2 & 0.006 & 0.252 & -0.6 \\
\hline Wholesale trade & $\begin{array}{l}\text { Durable goods vehicles, construction } \\
\text { materials, machinery; non-durable goods } \\
\text { and groceries, petroleum products }\end{array}$ & 0.026 & 0.008 & -2.6 & 0.021 & 0.029 & -2.1 \\
\hline \multicolumn{8}{|l|}{ Occupation: } \\
\hline Technical and related support & $\begin{array}{l}\text { Health technician, science technician, } \\
\text { aeroplane pilots }\end{array}$ & -0.064 & $<0.001$ & 6.2 & -0.064 & $<0.001$ & 6.2 \\
\hline Handlers, helpers, labourers & $\begin{array}{l}\text { Helpers - mechanics, construction, } \\
\text { freight-stock-material handlers, service } \\
\text { station staff }\end{array}$ & -0.063 & $<0.001$ & 6.1 & -0.058 & $<0.001$ & 5.6 \\
\hline Transport, material moving & $\begin{array}{l}\text { Truck-bus-cab drivers, ship } \\
\text { captains-mates-sailors, railway, material } \\
\text { movers, crane, grader, dozer, scraper }\end{array}$ & -0.051 & $<0.001$ & 5.0 & -0.050 & $<0.001$ & 4.9 \\
\hline Executive, administration, and management & $\begin{array}{l}\text { Legislators, financial managers, accounts } \\
\text { auditors }\end{array}$ & -0.051 & $<0.001$ & 4.9 & -0.064 & $<0.001$ & 6.2 \\
\hline Service occupations & $\begin{array}{l}\text { Household-cooks, private child care, } \\
\text { protective police, fire, guards, food } \\
\text { preparation, health aides, barbers }\end{array}$ & -0.028 & $<0.001$ & 2.8 & -0.020 & $<0.001$ & 2.0 \\
\hline Professional & $\begin{array}{l}\text { Engineers, architects, surveyors, scientists, } \\
\text { teachers, librarians, social scientists }\end{array}$ & -0.027 & $<0.001$ & 2.6 & -0.033 & $<0.001$ & 3.2 \\
\hline Precision production, craft, and repair & $\begin{array}{l}\text { Mechanics, repairers, heating, ventilating, and } \\
\text { air conditioning, construction trades, tool and } \\
\text { die makers, butchers and meat cutters }\end{array}$ & -0.014 & $<0.001$ & 1.4 & -0.015 & $<0.001$ & 1.5 \\
\hline Administrative support including clerical & $\begin{array}{l}\text { Supervisors, computer equipment operators, } \\
\text { secretaries, tellers, postal clerks }\end{array}$ & -0.012 & 0.261 & 1.2 & -0.010 & 0.373 & 1.0 \\
\hline Farming, forestry, and fishing & $\begin{array}{l}\text { Farm or nursery managers and workers, } \\
\text { loggers and cutters, fishers, hunters and } \\
\text { trappers }\end{array}$ & -0.011 & 0.006 & 1.1 & -0.008 & 0.050 & 0.8 \\
\hline Sales occupations & Sales representatives, financial and business & 0.001 & 0.886 & -0.1 & 0.003 & 0.582 & -0.3 \\
\hline Machine operators, assembly, and inspectors & $\begin{array}{l}\text { Metalworking, fabricating machine operator, } \\
\text { woodworking operator, fabricators, } \\
\text { production inspector }\end{array}$ & 0.016 & 0.032 & -1.6 & 0.018 & 0.018 & -1.8 \\
\hline
\end{tabular}

$\mathrm{p}$ Value associated with a test that the (trend) parameter $=0$ ( 2 tailed).

$\star$ est $=$ estimate of the (trend) parameter associated with year in "adjusted" or "unadjusted" model; \%decline = $100(1-\exp (\mathrm{b} 1))$ where b1 is the estimate of the (trend) parameter.

†Adjusted model $=\log$ (injury rate $)=\beta_{0}+\beta_{1}$ (year-83) $+f($ race, sex, age) where race is a 3 level categorical variable; sex is a 2 level categorical variable, and age is an 11 level categorical variable.

Unadjusted model $=\log$ (injury rate) $=\beta_{0}+\beta_{1}($ year-83).

reported for the youngest workers and smaller declines than reported for the oldest workers.

\section{Discussion}

One well documented potential problem with use of death certificate data is that of undercounting fatal injuries or employment. Death certificates may systematically undercount certain levels of the predictor variables. Further, the use of the number of employed workers as opposed to cumulative hours worked may skew the analysis in industries and occupations that have many part time workers. Discussion of the limitations of both the death certificate and the employment data can be found in various sources including $\mathrm{NIOSH}^{1}$ and Stout et $a .^{2}$ Finally, although the period covered by this analysis is reasonably long (10 years), in the interest of surveillance, the decrement in rates of fatal injuries should be reassessed as future years of data are available.
The overall unadjusted decline in rates of fatal injuries of $3.4 \%$ a year was similar to the $3.7 \%$ decrement reported by Stout et al for all industries combined over the period 1980-9. By comparison with the analysis of Stout et $a l^{2}{ }^{2}$ table 3 shows that the estimated changes for the individual industries were all smaller - this can be explained, in part, by different, although overlapping, periods along with the use of a model based calculation of trend. Clear differences in rates of fatal injuries were also present for each of the demographic variables. More detailed analysis and discussions of trends in rates of fatal injuries over levels of these variables can be found in various sources. ${ }^{23}$

An important extension and contribution of the present analysis was the examination of changes in excess of demographic and employment influences. Our goal, in this adjusted analysis, was to evaluate whether the trends in occupational fatal injuries in various industries 

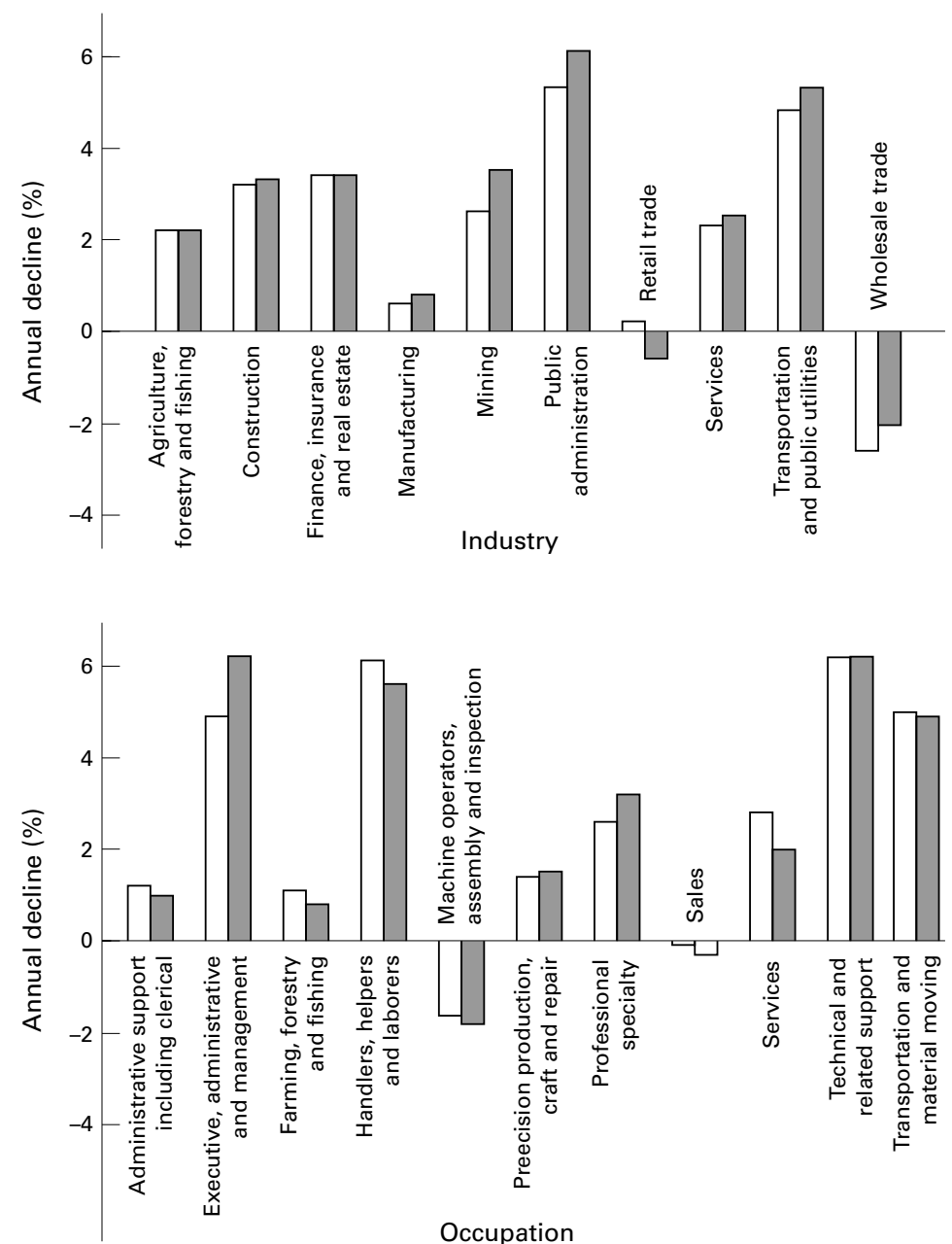

Bar plots of unadjusted (unshaded, open bars) and adjusted (shaded bars) estimates of the annual decline in rates of occupational fatal injuries for different industries and occupations. Positive entries imply a declining rate of fatal injuries whereas negative entries imply increasing rates. groups are appropriate targets for both additional analysis and injury prevention efforts. The modification of the trend by age also suggests an area for future study. Why are the oldest workers experiencing increases? Why are younger workers showing a decline that levels off with aging?

It is encouraging that the risk of dying from an injury at work is decreasing overall, and in most industry and occupational groups. Although race, sex, and age play a part, there are clearly other factors as well as demographic characteristics that influence the trend in risk of fatal injuries. Hypotheses and discussion of potential reasons for changes in rates have been presented by others, ${ }^{2}$ and more definitive studies of other contributing factors are clearly warranted.

Identifying and measuring the effects of injury prevention efforts and other causal factors contributing to reductions in risk are difficult on a national basis with surveillance data alone. However, these data can be used effectively to increase our understanding of the part various elements play in occupational risk. By factoring out the effects of changing employment patterns (through the computation of rates), proportioning out the effects of demographic characteristics (through models such as this), and examining the resultant trends within industry and occupational groups, we can begin to narrow the field of factors potentially contributing to the risk of fatal occupational injuries, and improve progress towards reduction of that risk.

We are grateful to Lynn Jenkins of the NIOSH in obtaining an electronic version of the NTOF data, and to Bob McIntire of the BLS for his assistance in obtaining an electronic version of the employment data that served as the denominator in the rate modelling portion of this study. The comments and review of this manuscript by Drs Cindy Robinson, Gordon Smith, and Rick Waxweiler led to an improved presentation. Finally, we are grateful for the input of three anonymous reviewers whose comments improved the clarity and quality of this presentation.

or occupations persisted after the changes associated with workplace demographics (race, age, sex) were factored out. If the injury rate in a particular industry was not decreasing, but the workforce had shifted with time to workers with lower risks of fatal injury-for example, greater mix of women or younger workersthen a decreasing trend in unadjusted rates of fatal injuries might be found in this particular industry simply due to the change in the demographics of the workforce.

The results of this analysis suggested a significant downward trend in rates of fatal injuries over the years 1983-92, above and beyond changes in the distribution of race, sex, and age. For most industries and occupations, the combination of race-sex-age contributed from $0.2 \%$ to $6.2 \%$ a year to the decline. Significant increases in adjusted rates of fatal injuries found in the wholesale trade industry and in the occupations of machine operators, assemblers, and inspectors, suggest that these
1 NIOSH. Fatal injuries to workers in the United States, 19809: a decade of surveillance. Cincinnati, Ohio: National Institute publication NIOSH No 93-108S.)

2 Stout NA, Jenkins EL, Pizatella TJ. Occupational injury mortality rates in the United States: changes from 1980 to 1989. Am f Public Health 1996;86:73-7.

3 Bell CA, Stout NA, Bender TR, et al. Fatal occupational injuries in the United States, 1980 through 1985. $7 A M A$ 1990;263:3047-50.

4 Office of Management and Budget. Standard industrial classification manual. Washington, DC: Office of Manageclassification manual. Washi

5 US Department of Commerce, Bureau of the Census. 1980 Census of population: alphabetic index of industries and occupations. Washington, DC: USDCBC,1982. (Publication PHC80-R3.)

6 US Bureau of the Census. The current population survey: design and methodology. Washington, DC: USBC, 1978. (Technical paper 40.)

7 McCullagh P, Nelder J. Generalized linear models, 2nd ed. London: Chapman and Hall, 1989.

8 Dobson, A. An introduction to generalized linear models. London: Chapman and Hall, 1990.

9 SAS. The GENMOD procedure. Cary, NC: SAS, 1993. (SAS Tech Report P-243.

10 Bailer AJ, Reed LD, Stayner LT. Modeling fatal injury rates using Poisson regression: a case study of workers in agriculture, forestry and fishing. Fournal of Safety Research 1997;28:177-86. for Occupational Safety and Health, 1993. (DHHS 